Instrumental A chievements

\title{
Direct Electrospray Ionization Mass Spectroscopic Measurement of Micro-Flow Oil/Water System
}

\author{
Hitoshi Watarai, ${ }^{\dagger}$ Atsushi Matsumoto, and Takao Fukumoto \\ Department of Chemistry, Graduate School of Science, Osaka University, Toyonaka, Osaka 560-0043, Japan
}

(Received October 22, 2001; Accepted December 17, 2001)

Electrospray ionization (ESI) is a versatile and effective ionization technique of liquid samples for various mass spectrometric (MS) measurements. Therefore, ESI is widely used as an interface in MS detection for CE, ${ }^{1}$ HPLC $^{2}$ and combinatorial separation systems. ${ }^{3}$ The advantages of ESI/MS in solution chemistry research are also recognized because of its high potential in the structural identification or chemical speciation of compounds formed in diluted solutions. ${ }^{4}$ In some cases, the chemical equilibria and kinetics of complexation in a solution as well as in a gas phase could be studied by ESI/MS. ${ }^{5}$

However, the solvents usable in ESI/MS are usually limited to polar or protic solvents, such as methanol, ethanol, acetonitrile, dimethylsulfoxide and water. Therefore, non-polar organic solvents, which can solubilize highly hydrophobic compounds, are difficult to be used in an ordinal ESI/MS. For example, heptane and toluene, which are used very often in the solvent extraction of trace amounts of metal ions or organic compounds in environmental samples, can not be introduced directly to ESI, because of their very low conductivities. ${ }^{6}$ If these kinds of inert solvents could be used in ESI/MS, the variety of samples in ESI/MS must be significantly extended.

The present study reports a method to introduce an inert organic phase into ESI/MS by producing organic droplets in a flowing aqueous phase at the point just prior to ionization. This method is applicable for ESI/MS measurements of very small amounts of hydrophobic compounds that can be dissolved or extracted into an inert organic solvent. As an example, a hydrophobic extractant, 2-(5-bromo-2-pyridylazo)-5-diethylaminophenol (5Br-PADAP, or HL), in toluene was employed. The distribution constant $\left(\log K_{\mathrm{D}}\right)$ of 5-Br-PADAP, obtained as 4.78 in toluene/water, proved its high hydrophobicity. Furthermore, the solvent extraction of $\mathrm{Cu}$ (II) with 5-Br-PADAP in toluene was attempted in a two-phase flow system.

Figure 1 shows a schematic drawing of the electrospray ionization interface of the micro-flow liquid-liquid extraction system. The interface is composed of an outer stainless-steel capillary ( $0.4 \mathrm{~mm}$ o.d., $0.2 \mathrm{~mm}$ i.d.) and an inner silica capillary (0.158 $\mathrm{mm}$ o.d., $0.050 \mathrm{~mm}$ i.d.). The tip of the silica capillary was made as fine as $13 \mu \mathrm{m}$ o.d. and $7 \mu \mathrm{m}$ i.d. by pulling it under heating with a $\mathrm{CO}_{2}$ laser (SYNRAD, $10.5 \mu \mathrm{m}$ wavelength, 12.0 $\mathrm{W}, 3 \mathrm{~mm}$ beam waist). The end of the silica capillary tip was positioned about $1 \mathrm{~mm}$ inside from the end of the outer stainless-steel capillary. A water-saturated toluene phase containing $1.0 \times 10^{-3} \mathrm{M}$ 5-Br-PADAP was pumped in the inner

\footnotetext{
† To whom correspondence should be addressed.

E-mail: watarai@chem.sci.osaka-u.ac.jp
}

silica capillary at a flow rate of $0.001-0.02 \mathrm{ml} / \mathrm{h}$. Into the outer stainless-steel capillary, $5.0 \times 10^{-6} \mathrm{M} \mathrm{Cu}(\mathrm{II})$ in the aqueous $0.0010 \mathrm{M}$ acetic acid was introduced from a PTFE tee connector at a flow rate of $0.1 \mathrm{ml} / \mathrm{h}$ as an outer aqueous phase. For pumping both phases, two syringe pumps (Harverd 11) were used. A high voltage of $2-5 \mathrm{kV}$ was applied by a power supply (Glassman) to the stainless-steel for generating an electrospray. The ESI stainless-steel tip was positioned about $2 \mathrm{~cm}$ apart from the inlet hole in an interface plate (controlled at $600 \mathrm{~V}$ ) of the TOF/MS (Jaguar, Sensar, Utah). Electrospray was generated at a voltage higher than $3.5 \mathrm{kV}$, which was applied to the ESI stainless-steel tip. A stable spray was obtained at $4.4 \mathrm{kV}$; this condition was adopted in the measurement. Nitrogen curtain gas was flowed at a rate of $1000 \mathrm{ml} / \mathrm{min}$ between the interface and a nozzle positioned just inside the interface. The nozzle voltage was changed over the range of $100-500 \mathrm{~V}$, and the voltage in the skimmer was set at $70 \mathrm{~V}$. The acquisition rate of the MS spectra was $5000 \mathrm{spectra} / \mathrm{s}$ and the resolution was 1000 at $1000 \mathrm{~m} / \mathrm{z}$.

Under the conditions of $0.02 \mathrm{ml} / \mathrm{h}$ for the flow rate of the organic phase and $400 \mathrm{~V}$ for the nozzle voltage, a good ESI/MS spectrum was obtained, as shown in Fig. 2. Two dominant peaks of a 1:1 complex $(\mathrm{m} / \mathrm{z}=412)$ and a 1:2 complex $(\mathrm{m} / \mathrm{z}=$ $760)$ of $\mathrm{Cu}(\mathrm{II})$ with 5-Br-PADAP were clearly detected as well as the free extractant $(\mathrm{m} / \mathrm{z}=349)$. When the aqueous phase was free of $\mathrm{Cu}(\mathrm{II})$, only the peak of 5-Br-PADAP $(\mathrm{m} / \mathrm{z}=349)$ was measured. The peaks of 412 and 760 were observed only in the presence of both $\mathrm{Cu}(\mathrm{II})$ and 5-Br-PADAP. These assignments of the peaks were confirmed from the influence of a natural isotope abundance for ${ }^{63} \mathrm{Cu} /{ }^{65} \mathrm{Cu}$ and ${ }^{79} \mathrm{Br} /{ }^{81} \mathrm{Br} .{ }^{5}$ From these results, it was concluded that the two-phase flow ESI/MS could detect a highly hydrophobic solute, like a 5-Br-PADAP. Furthermore, the complexes formed in the two-phase system were clearly detected by ESI/MS by the present method.

The nozzle voltage was one of the critical conditions to be optimized for the detection of hydrophobic compounds. When the nozzle voltage was less than $300 \mathrm{~V}$, solvent cluster peaks, mainly of water molecules, became larger and the signal of the metal complex was not observed. At $500 \mathrm{~V}$, both the metal complex peaks and the solvent cluster peaks were decreased. At $400 \mathrm{~V}$, the metal complex signals were highest and the solvent cluster peaks were lowest. These phenomena could be understood in terms of collision activated dissociation (CAD). Because CAD was increased at a higher nozzle voltage, a higher voltage effectively reduced the background signals of the solvent clusters, and then enhanced the signals of HL and its complexes.

The flow rate of the organic phase was another critical condition to be optimized. Accompanied by an increase of the 


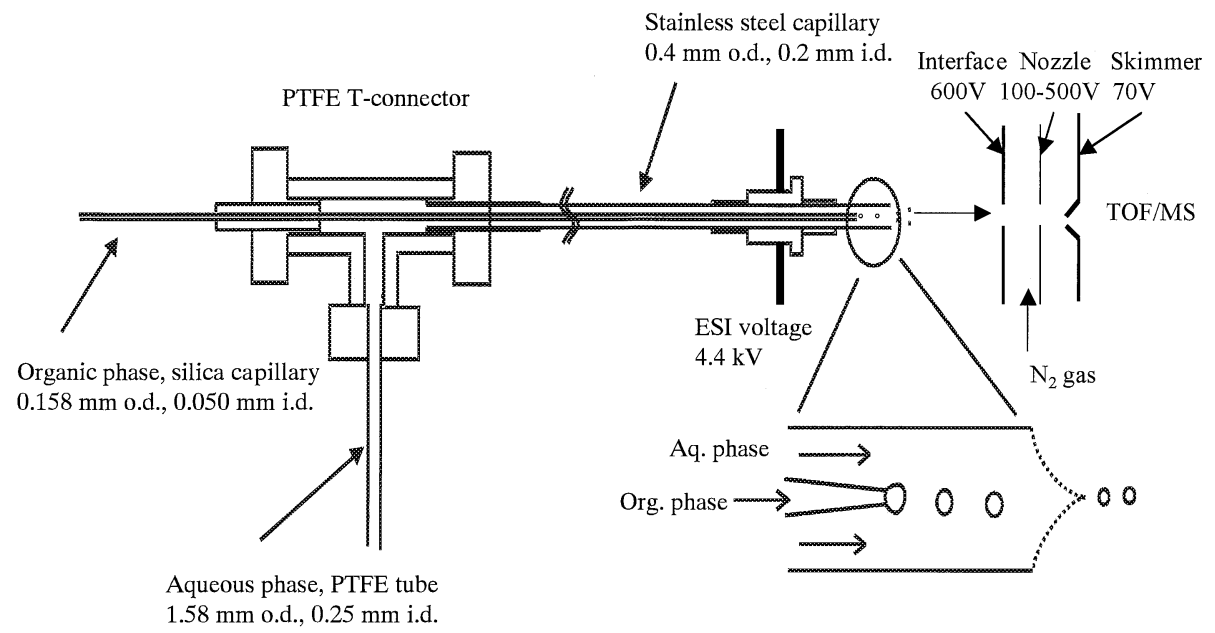

Fig. 1 Schematic drawing of the electrospray ionization (ESI) interface of a two-phase micro-flow system.

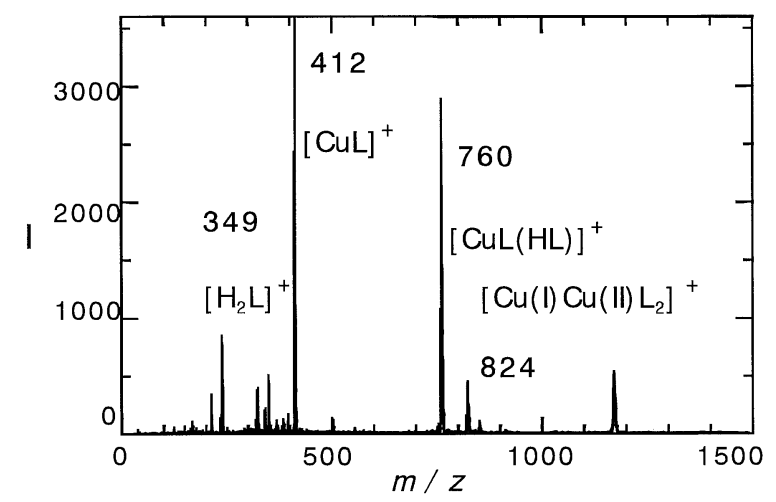

Fig. 2 ESI/Mass spectrum of copper(II)-5-Br-PADAP complexes in a micro-flow toluene-water system including $1.0 \times 10^{-3} \mathrm{M} 5-\mathrm{Br}-$ PADAP in the organic phase at a flow rate of $0.02 \mathrm{ml} / \mathrm{h}$ and $5.0 \times$ $10^{-6} \mathrm{M} \mathrm{Cu}(\mathrm{II})$ in aqueous $0.0010 \mathrm{M}$ acetic acid with at a flow rate of $0.1 \mathrm{ml} / \mathrm{h}$.

flow rate of the organic phase from $0.001 \mathrm{ml} / \mathrm{h}$ to $0.02 \mathrm{ml} / \mathrm{h}$, the signal of the free ligand was decreased and that of the complex was increased, indicating that an increase in the amount of 5-BrPADAP at a higher flow rate proceeded the formation of its $\mathrm{Cu}$ (II) complex in the organic phase or the interface.

The interfacial activity of $\mathrm{Cu}(\mathrm{II})-5-\mathrm{Br}-\mathrm{PADAP}$ was investigated by means of a high-speed stirring method. ${ }^{7}$ Fifty milliliters of a toluene phase containing $2.0 \times 10^{-5} \mathrm{M} 5$-Br$\mathrm{PADAP}$ and an equal volume of an aqueous phase containing $1.0 \times 10^{-5} \mathrm{M} \mathrm{Cu}(\mathrm{II})$ at $\mathrm{pH}=6.36$ were vigorously stirred for ten $\mathrm{min}$ at $5000 \mathrm{rpm}$, and then phase-separated at $200 \mathrm{rpm}$. During these operations, the uv/vis absorption spectra of the organic phase were observed continuously. The measurement clearly indicated that a 1:1 complex of $\mathrm{Cu}(\mathrm{II})-5-\mathrm{Br}-\mathrm{PADAP}$ was highly adsorptive at the toluene-water interface which was generated by stirring. The 1:2 complex could be extracted into the toluene phase only when the high-speed stirring (5000 rpm) was ceased and the interfacial area was decreased by almost one five hundredth. ${ }^{7}$ Therefore, it was strongly suggested that the $1: 1$ complex was produced at the interface of a droplet during its generation at the tip of the inner capillary.

In conclusion, a new technique of two-phase micro-flow electrospray ionization/mass spectrometry was proposed in the present study. Toluene droplets containing a hydrophobic compound produced in a flowing aqueous phase in a stainlesssteel capillary were directly served for ESI/MS spectrometry. This technique was successfully applied for the detection of a hydrophobic pyrizylazo extractant in toluene and its $\mathrm{Cu}(\mathrm{II})$ complexes extracted into the organic phase or adsorbed at the interface in the two-phase micro-flow system. Further study will show how this technique is promising for the detection of metal complexes formed at the liquid-liquid interfaces in solvent-extraction systems. By the way, the present technique has overcome one of the drawbacks of the ESI/MS method concerning the solvents used.

\section{Acknowledgements}

This work was supported by a Grant-in-Aid for Scientific Research (A) (No. 12304045) and Scientific Research of Priority Areas (B) No. 757 (No. 13129204) from the Ministry of Education, Culture, Sports, Science and Technology of Japan.

\section{References}

1. R. D. Smith, C. J. Barinaga, and H. R. Udseth, Anal. Chem., 1988, 60, 1948; T. G. Huggins and J. D. Henion, Electrophoresis, 1993, 14, 531; J.-T. Wu, M. G. Qian, M. X. Li, L. Liu, and D. M. Lubman, Anal. Chem., 1996, 68, 3388; D. P. Kirby, J. M. Thorne, W. K. Gotzinger, and B. L. Karger, Anal. Chem., 1996, 68, 4451.

2. K. W. M. Siu, R. Guevremont, J. C. Y. Le Blanc, G. J. Gardner, and S. S. Berman, J. Chromatogr., 1991, 554, 27; M. Kohler and J. A. Leary, Anal. Chem., 1995, 67, 3501.

3. R. B. Cole, "Electrospray Ionization Mass Spectrometry: Fundamentals, Instrumentation, and Applications", 1997, John Wiley \& Sons, New York.

4. K. Wang, X. Han, R. W. Gross, and G. W. Gokel, J. Am. Chem. Soc., 1995, 117, 7680; G. E. Hofmeister, Z. Zhou, and J. A. Leary, J. Am. Chem. Soc., 1991, 113, 5964.

5. A. Matsumoto, T. Fukumoto, H. Adachi, and H. Watarai, Anal. Chim. Acta, 1999, 390, 193.

6. R. J. Pfeifer and C. D. Hendricks, AIAA J., 1968, 6, 496.

7. H. Watarai, M. Gotoh, and N. Gotoh, Bull. Chem. Soc. Jpn., 1997, 70, 957. 